\title{
Sustainability Research on Promoting the Inheritance of Lacquer Art Based on the E-learning Mode-Case Study of the Popularization of Lacquer Art Education in Primary Schools in Guangzhou Area
}

\author{
Kuo-Kuang Fan ${ }^{1}$, Xue-Hui Li ${ }^{1, *}$ and Meng-Jia Lu ${ }^{2}$ \\ 1 Graduate School of Design, National Yunlin University of Science \& Technology, \\ Douliou 64002, Yunlin, Taiwan; fankk@yuntech.edu.tw \\ 2 Guangzhou High School of Fine Arts, Guangzhou 510060, Guangdong, China; tl-4@163.com \\ * Correspondence: sophieli1983@hotmail.com
}

Received: 21 January 2020; Accepted: 11 March 2020; Published: 12 March 2020

check for updates

\begin{abstract}
This paper investigates the sustainable inheritance of contemporary lacquer art in the Guangzhou area. Based on the traditional teaching mode dominated by folk inheritance and university education, this paper develops the advantage of contemporary information technology and proposes the application of the e-learning mode to assist the popularization of lacquer art education in society, which plays a positive role in promoting the sustainable development of the lacquer art culture in Guangzhou. This study adopts literature analysis and the questionnaire survey method, and then integrates this learning mode into the lacquer art learning curriculum in primary schools. Finally, this paper summarizes and reflects on the teaching results, and presents the effective role of this model in promoting the teaching of lacquer art culture, which is of important practical significance for consolidating the sustainable development of contemporary lacquer art culture.
\end{abstract}

Keywords: sustainable development and inheritance of lacquer art; e-learning; Guangzhou area; popularization education

\section{Introduction}

\subsection{Research Background}

This research, based upon teaching practices, puts forward the mode of promoting the inheritance of lacquer art via combined application of e-learning during the popularization education stage of primary schools in the Guangzhou area. This is an extension and supplement to the traditional educational mode for lacquer art based on the sustainable development of local lacquer culture. China's lacquer art culture has a long history, in which Guangzhou plays an important role. The traditional inheritance methods mainly include two aspects: folk workshop inheritance and university curriculum education.

The folk factory or workshop inheritance model has been established for a long time, and although it has previously experienced a downturn with the promotion of intangible cultural heritage by the state and the improvement of the craft esthetic ability in contemporary society, folk inheritance has now formed a balanced and effective cyclic relationship. Whether universities have a formal professional setting for lacquer art or just regard it as a short-term minor course, after decades of reorganization and integration, lacquer art teaching in major universities is now offered as a complete set of curriculum programs. The faculty of the current lacquer art teaching system mostly originates from university training. 
However, both folk inheritance and university education suffer from an extremely limited scope of teaching subjects. Contemporary lacquer art is not widely popular in current society, and the public rarely have the opportunity to approach lacquer art culture in person. In addition, there is very little knowledge related to lacquer art in classroom teaching in middle and primary schools; thus, adolescents lack the knowledge of lacquer art. In middle and primary schools, knowledge of lacquer art culture has not been effectively or widely transmitted, which has imposed great restrictions on the future development of lacquer art, both in terms of folk inheritance and university education.

Therefore, in order to consolidate the sustainable development of lacquer art inheritance in the Guangzhou area, this paper aims to establish a contemporary model benefiting the popularization teaching of lacquer art culture. In order to collect the relevant data of lacquer art professionals during their studies, active lacquer art creators aged between 25-45 years in the Guangzhou area were surveyed through online questionnaires (Table 1); 26 questionnaires were distributed, and 22 recovered, resulting in 17 valid questionnaires and 5 invalid questionnaires. Respondents were required to be engaged in (or have at least once engaged in) lacquer art planning or creation, and this study focuses on exploring their initial contact channels and origins of lacquer art.

Table 1. Content of questionnaire survey on lacquer art professionals and proportions of options in the Guangzhou area.

\begin{tabular}{|c|c|}
\hline No. & $\begin{array}{c}\text { Content of Questionnaire Survey on Lacquer Art Professionals and Proportions of Options } \\
\text { in the Guangzhou Area }\end{array}$ \\
\hline \multirow{3}{*}{1} & How old are you? \\
\hline & A. $25-30$ years old $(23.5 \%)$ \\
\hline & D. $40-45$ years old $(11.8 \%)$ \\
\hline \multirow{3}{*}{2} & What is your highest academic qualification? \\
\hline & $\begin{array}{ll}\text { A. Vocational college }(0 \%) & \text { B. Undergraduate degree }(29 \%)\end{array}$ \\
\hline & D. Doctoral degree $(18 \%)$ \\
\hline \multirow{3}{*}{3} & How were you first exposed to lacquer art? \\
\hline & B. Family environment $(12 \%)$ \\
\hline & C. Public exhibitions or publications (23\%) $\quad$ D. Digital platforms $(0 \%)$ \\
\hline \multirow{3}{*}{4} & Which of the following ways do you prefer to learn about lacquer art? \\
\hline & A. Publications $(6 \%) \quad$ B. Consult experts or watch exhibitions $(82 \%)$ \\
\hline & C. Movies or television $(0 \%)$ \\
\hline \multirow{3}{*}{5} & $\begin{array}{c}\text { When was the last time you were exposed to lacquer art (including remote viewing, } \\
\text { understanding the lacquer art theory, etc.)? }\end{array}$ \\
\hline & $\begin{array}{ll}\text { A. Within the last week }(70 \%) & \text { B. Within the last three months }(6 \%)\end{array}$ \\
\hline & C. Within the last year $(12 \%)$ \\
\hline
\end{tabular}

According to the survey results, most of the respondents were young and middle-aged, and their enlightenment of lacquer art mainly originated from school classrooms (Figure 1). No respondents expressed that they initially obtained the knowledge of lacquer art through digital platforms (Table A1). In the past, due to the limitations of electronic technology, digital platforms did not play an important role in the inheritance of lacquer art. However, with the development of Internet configuration and digital platform equipment of the Guangzhou area in the past ten years, people have increasingly embraced diversified learning methods through the Internet. Under such a background, this research introduced the e-learning mode into the inheritance education of the lacquer art culture, and applied this mode to the popularization teaching of lacquer art culture, thus laying a solid foundation for the sustainable development of lacquer art. 


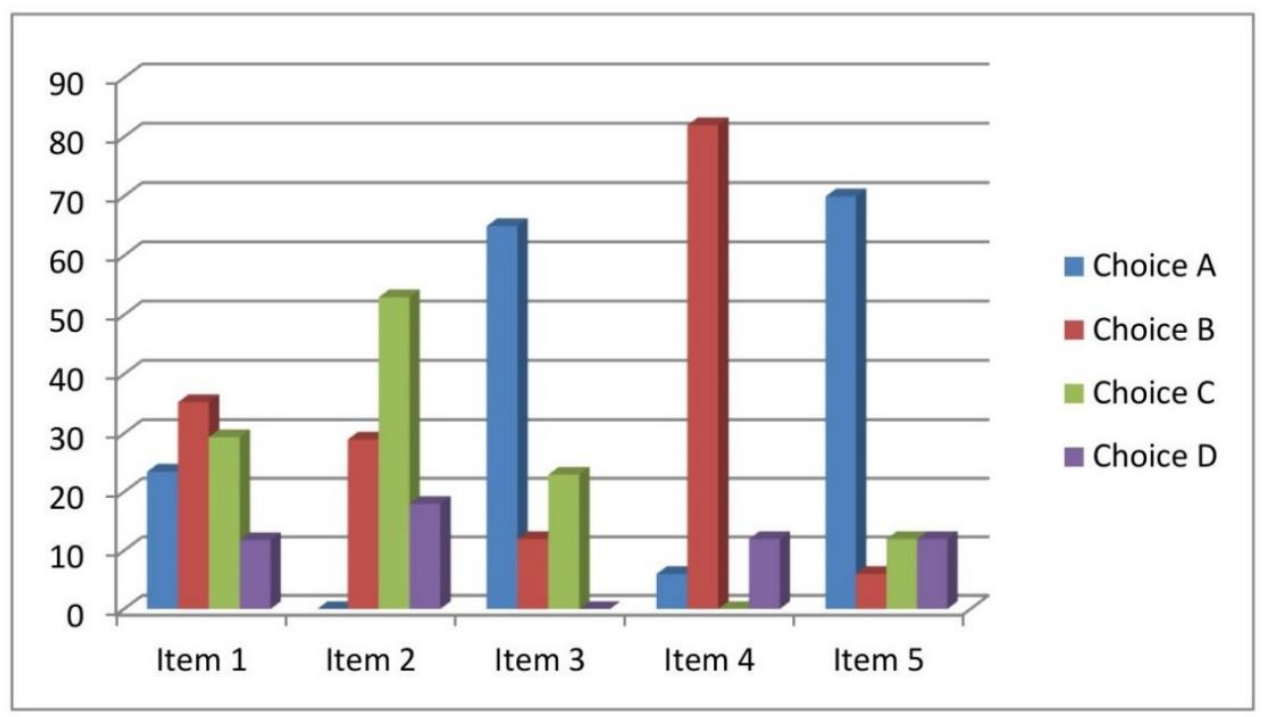

Figure 1. Questionnaire survey results of lacquer art professionals in the Guangzhou area.

\subsection{Research Purpose}

This study applied the e-learning mode to assist the inheritance of lacquer art. Based on action research in primary schools, this paper explored the positive significance of the e-learning mode in the sustainable development of lacquer art in Guangzhou.

\section{Literature Review}

\subsection{Sustainable Development of the Inheritance of Contemporary Lacquer Art in the Guangzhou Area}

This study focuses on the sustainability of lacquer art culture education in the Guangzhou area. Lacquer art has a long history, and its early inheritance model is similar to the knowledge of most traditional craftsmanship. Ru-rui Shi once mentioned: "Lacquer art was previously never transmitted to outsiders as the family secret skills, and even only passed on to males instead of females. The craftsmen were reluctant to disclose their unique secret skills" [1] (pp. 72-73). During the Qing Dynasty, on the one hand, the export orders for lacquerware kept increasing steadily; on the other hand, as the local merchants were keen to decorate their courtyards with lacquer carvings, the folk lacquer art workshops in the South Guangdong area were very prosperous [2]. For a long time, the lacquer art workshops formed a sustainable development model based on apprenticeship and broad market prospects.

After a long period of warfare and turmoil during the Republic of China [3], the original export channels disappeared, and everyone had to make a living for their own lives, which greatly affected the lacquer art workshops and factories. It was not until half a century ago that the government re-invested in reviving lacquer art in response to the demand for export gifts. However, due to the long absence of lacquer artists, the hard and rigid learning life has made it difficult for apprentices to persist long-term, and the traditional stable structure of the folk workshops from the past have become history.

More importantly, modern lacquer art teaching is not limited to workshop inheritance, and has already been developed in some vocational universities; for example, in the Guangzhou area, the Guangzhou Academy of Fine Arts established a lacquer painting studio in 1971, and began to formally enroll students [4]. Although the number of students initially enrolled were low, standardized personnel training became the basis of sustainable lacquer art teaching. By the 21st century, the South China Normal University Academy of Fine Arts successfully applied for the qualification of establishing a master's degree program for "lacquer art and theoretical research" [5], and in 2012, the lacquer art program of the Guangzhou Academy of Fine Arts officially started to enroll graduate students [6]. In addition, Guangdong University of Education, Guangzhou University, and other 
advanced education institutions have also opened professional courses related to lacquer art, which has cultivated a large number of professional reserve talents for the teaching of lacquer art culture.

\subsection{About E-Learning}

Electronic Learning, abbreviated as e-learning, is a new model proposed under the globalization background of current digital technology [7-9]. According to the definition of the American Society for Training and Development, e-learning contains the teaching content and learning experience supported or led by Internet electronic technology $[10,11]$, which plays an important role for both teachers and students. E-learning is inseparable from the multimedia learning resources of the Internet [12], as it consists of online learning communities and Internet technology platforms, and all teaching activities are assisted by electronic media, such as the Internet, local area networks, extended networks, satellite signals, video media, etc. [13]. It is a new model for remote education [14].

Under the background of smooth electronic equipment and networks, a network learning environment is comprised of Internet multimedia learning resources, online learning communities, and Internet technology platforms, which contain massive learning resources, including data, files, software, and discussion groups, and thus, establishes a highly-integrated resource library [15-17]. E-learning, as based on computers and Internet technology, has become an important learning method and education model in information society, and can achieve a combination of digitized information and network with its core features in the improvement of traditional teaching modes, promoting teaching efficiency, enriching students' learning enthusiasm, and thus maintaining the sustainable development of learning state [18].

The e-learning mode for contemporary education plays a significant promotional role for the development of education $[7,13,14,19,20]$. As a necessary supplement to traditional education [21,22], e-learning highlights the role of learners in the education process, and positions teachers as guides and organizers [23]. It has many advantages: before the class, under the guidance of teachers, students can pre-review related knowledge through online platforms in advance; during the class, electronic devices can effectively transfer multi-directional video information; after the class, students can learn anytime and anywhere, regardless of time and space boundaries, and according to their own characteristics. Especially for the art and crafts teaching of primary school stages, despite the undoubtfully important direct visual esthetic, due to the common situation of inadequate course duration for face-to-face teaching, the educational mode of combined e-learning could make a good supplement to students' theoretical knowledge and is undoubtedly a teaching approach worth trying.

\section{Research Methods}

\subsection{Action Research}

This study aims to apply the e-learning mode to assist the teaching of lacquer art inheritance, which requires an action research method for experimental analysis, and then, integrates it into teaching practices in order to obtain objective data. In order to collect real-time feedback from the students, the researchers conducted action research by acting as the front-line teachers in the classroom, which is an effective method for teaching research.

The researchers engaged in research as front-line classroom teachers, selecting a short-term lacquer art practice course for a primary school in the Guangzhou area and all 13 students in the class as research objects. This course features the original intention to popularize lacquer art culture and it is expected that an approach to maintain the study, and to be sustained and extended upon, will be found. Based upon the research needs, the course is mainly composed of two parts (see detailed teaching procedures in the following sections): offline in-class practice training and assisted online e-learning learning.

Based upon the teaching practice, the researchers personally tutored the lacquer art techniques in class, timely established an online sharing platform with parents and students, selected significant videos and text-and-graphic data for sharing, and conducted analysis and made suggestions on 
students' lacquer works. After the lacquer art course, a questionnaire survey was administered to the students, with the intention of improving and exploring related research in the future.

\subsection{Questionnaire Survey}

According to the Preliminary Study on the Questions Related to the Development and Evaluation of Questionnaires, "the questionnaire is one of the most common tools used to collect data in modern society" [24] (p. 193). A questionnaire should be concise and centered on objective issues, which is conducive to empirical research [25]. The questionnaires were completed by respondents. In the closed-end questionnaire survey method, the questionnaires are typically distributed and collected through online platforms [26].

In light of the above literature analysis, a questionnaire survey is commonly adopted if there is a need to collect the objects' views and opinions during research. Closed-end questionnaire surveys were conducted twice in this paper: The first was based on lacquer art professionals in the Guangzhou area via online questionnaires, which mainly discussed their process and objective conditions of lacquer art learning; and the second, on the collection of after-class feedback from students participating in the practice course via paper questionnaires, the findings of which function as a significant basis to evaluate the effectiveness of this research.

\section{Research and Analysis}

\subsection{Research on the Popularization Teaching of Lacquer Art in Primary Schools Based on E-Learning}

With the widespread use of smartphones in the last ten years, the resource advantages of Internet platforms were applied to facilitate the spread of lacquer art knowledge in the entire society. In order to better cultivate children's interest in learning lacquer art, and to promote social attention, practical teaching methods were explored and more effective and diversified teaching methods were sought. In addition, the e-learning mode was introduced to promote the teaching of lacquer art culture, experiments in primary schools were conducted with the action research method, and the results were objectively analyzed. Finally, effective suggestions were proposed.

Based on the lacquer art practice course of the third- and fourth-grade students in Guangzhou primary schools (Table 2), this study explored the positive effects of the e-learning mode on the sustainable development of lacquer art. The details of the practice course and the steps are summarized in Tables 3 and 4.

Table 2. Background of students participating in the practice course of lacquer art.

\begin{tabular}{ccccc}
\hline $\begin{array}{c}\text { Students } \\
\text { Participated }\end{array}$ & Age & Gender & $\begin{array}{c}\text { Time for Formal } \\
\text { Learning of Fine Arts }\end{array}$ & $\begin{array}{c}\text { Ever Approached } \\
\text { Lacquer Art }\end{array}$ \\
\hline Student 1 & 8 & Female & 2 years & No \\
Student 2 & 8 & Female & 1.5 years & No \\
Student 3 & 8 & Male & 1.5 years & No \\
Student 4 & 9 & Female & 3 years & Yes \\
Student 5 & 8 & Female & 2 years & No \\
Student 6 & 9 & Female & 2.5 years & No \\
Student 7 & 8 & Female & 2 years & No \\
Student 8 & 9 & Female & 3 years & No \\
Student 9 & 8 & Male & 1 year & No \\
Student 10 & 8 & Male & 1 year & No \\
Student 11 & 8 & Female & 1.5 years & No \\
Student 12 & 9 & Female & 3 years & No \\
Student 13 & 9 & Female & 2 years & \\
\hline
\end{tabular}


Table 3. Details of the lacquer art practice course.

\begin{tabular}{cccc}
\hline Age & Number of Participants & Course Arrangement & Assignment Requirement \\
\hline $8-9$ years old & 13 & $\begin{array}{c}7 \text { classes (90 minutes per } \\
\text { class) }\end{array}$ & $\begin{array}{c}\text { One piece of lacquer art work and } \\
\text { one questionnaire }\end{array}$ \\
\hline
\end{tabular}

Table 4. Research steps of the lacquer art practice course.

\begin{tabular}{|c|c|c|c|}
\hline Teaching Period & Teaching Content & Assignment Progress & Teaching Tools \\
\hline Lesson 1 & $\begin{array}{l}\text { Briefly introduce the lacquer } \\
\text { art culture, explain the } \\
\text { specific arrangements for } \\
\text { each class, and establish the } \\
\text { class groups }\end{array}$ & $\begin{array}{l}\text { Draft with black marker, and } \\
\text { emphasize the relationship } \\
\text { between black and white. } \\
\text { The pattern should not be } \\
\text { too small }\end{array}$ & $\begin{array}{l}\text { Computer multimedia } \\
\text { equipment, white paper, } \\
\text { black marker }\end{array}$ \\
\hline $\begin{array}{l}\text { e-learning Afterschool } \\
\text { learning }\end{array}$ & $\begin{array}{l}\text { Use the Internet to post } 10 \\
\text { photos of lacquer art works } \\
\text { of past generations on } \\
\text { WeChat. }\end{array}$ & $\begin{array}{c}\text { Carefully appreciate the } \\
\text { works and discuss with } \\
\text { parents. }\end{array}$ & $\begin{array}{c}\text { Smartphone or computer, } \\
\text { WIFI. }\end{array}$ \\
\hline Lesson 2 & $\begin{array}{c}\text { Analyze the basic lacquer art } \\
\text { techniques, and ask students } \\
\text { to apply the primer by } \\
\text { themselves. }\end{array}$ & $\begin{array}{l}\text { Apply a primer to the } \\
\text { surface of the wooden spoon, } \\
\text { and then, modify the } \\
\text { drawing. }\end{array}$ & $\begin{array}{l}\text { Computer multimedia } \\
\text { equipment, Bottom paint, } \\
\text { wooden spoon. }\end{array}$ \\
\hline $\begin{array}{l}\text { e-learning Afterschool } \\
\text { learning }\end{array}$ & $\begin{array}{l}\text { Post } 10 \text { pictures of farmers } \\
\text { collecting the rough lacquer } \\
\text { in WeChat groups with text } \\
\text { descriptions. }\end{array}$ & $\begin{array}{l}\text { Ask students to view the } \\
\text { pictures and text } \\
\text { descriptions to understand } \\
\text { the origins of lacquer. }\end{array}$ & $\begin{array}{c}\text { Smartphone or computer, } \\
\text { WIFI. }\end{array}$ \\
\hline Lesson 3 & $\begin{array}{l}\text { Briefly explain the origin of } \\
\text { raw lacquer art materials, } \\
\text { and ask students to use chalk } \\
\text { for drafting. }\end{array}$ & $\begin{array}{l}\text { Use white chalk to finalize } \\
\text { on a lacquered wooden } \\
\text { spoon, and start to partially } \\
\text { color the works. }\end{array}$ & $\begin{array}{l}\text { Computer multimedia } \\
\text { equipment, lacquer art } \\
\text { creation materials. }\end{array}$ \\
\hline $\begin{array}{l}\text { e-learning Afterschool } \\
\text { learning }\end{array}$ & $\begin{array}{l}\text { Post videos of several } \\
\text { common lacquer art } \\
\text { techniques to the WeChat } \\
\text { group. }\end{array}$ & $\begin{array}{l}\text { Ask students to watch the } \\
\text { videos and prepare to } \\
\text { practice in class. }\end{array}$ & $\begin{array}{c}\text { Smartphone or computer, } \\
\text { WIFI. }\end{array}$ \\
\hline Lesson 4 & $\begin{array}{l}\text { Demonstrate common } \\
\text { lacquer art techniques on } \\
\text { site, and emphasize the } \\
\text { technical difficulties. }\end{array}$ & $\begin{array}{l}\text { Continue lacquer art } \\
\text { creation, and strengthen the } \\
\text { outline. }\end{array}$ & $\begin{array}{l}\text { Computer multimedia } \\
\text { equipment, lacquer art } \\
\text { creation materials. }\end{array}$ \\
\hline $\begin{array}{l}\text { e-learning Afterschool } \\
\text { learning }\end{array}$ & $\begin{array}{l}\text { Send "Masters in The } \\
\text { Forbidden City (I)" to the } \\
\text { group. }\end{array}$ & $\begin{array}{l}\text { Pay attention to the lacquer } \\
\text { art section and invite parents } \\
\text { to observe the works } \\
\text { together. }\end{array}$ & $\begin{array}{c}\text { Smartphone or computer, } \\
\text { WIFI. }\end{array}$ \\
\hline Lesson 5 & $\begin{array}{l}\text { Periodically comment on } \\
\text { student works, and teach the } \\
\text { polishing steps and } \\
\text { techniques. }\end{array}$ & $\begin{array}{l}\text { Use sandpaper to properly } \\
\text { polish the surface of the } \\
\text { works, and delineate details. }\end{array}$ & $\begin{array}{l}\text { Computer multimedia } \\
\text { equipment, lacquer art } \\
\text { creation materials. }\end{array}$ \\
\hline $\begin{array}{l}\text { e-learning Afterschool } \\
\text { learning }\end{array}$ & $\begin{array}{l}\text { Send "Masters in The } \\
\text { Forbidden City (II)" to the } \\
\text { group. }\end{array}$ & $\begin{array}{l}\text { Pay attention to the repair of } \\
\text { lacquer art, and } \\
\text { communicate with parents. }\end{array}$ & $\begin{array}{c}\text { Smartphone or computer, } \\
\text { WIFI. }\end{array}$ \\
\hline Lesson 6 & $\begin{array}{l}\text { Discuss the contents of "I am } \\
\text { repairing cultural relics in } \\
\text { the Forbidden City" with the } \\
\text { students, and demonstrate } \\
\text { the application of metal foil. }\end{array}$ & $\begin{array}{l}\text { Polish the works, exhibit the } \\
\text { texture of lacquer art, and } \\
\text { locally apply metal foil. }\end{array}$ & $\begin{array}{l}\text { Computer multimedia } \\
\text { equipment, lacquer art } \\
\text { creation materials. }\end{array}$ \\
\hline
\end{tabular}


Table 4. Cont.

\begin{tabular}{|c|c|c|c|}
\hline Teaching Period & Teaching Content & Assignment Progress & Teaching Tools \\
\hline $\begin{array}{c}\text { e-learning Afterschool } \\
\text { learning }\end{array}$ & $\begin{array}{l}\text { Send "Masters in The } \\
\text { Forbidden City (III)" to the } \\
\text { group. }\end{array}$ & $\begin{array}{l}\text { If there are some parts in the } \\
\text { video difficult to be } \\
\text { understood, please record } \\
\text { them and discuss with the } \\
\text { teachers in class. }\end{array}$ & $\begin{array}{c}\text { Smartphone or computer, } \\
\text { WIFI. }\end{array}$ \\
\hline Lesson 7 & $\begin{array}{l}\text { Guide the lacquer covering } \\
\text { process, and interact with } \\
\text { the students for the last half } \\
\text { hour. }\end{array}$ & $\begin{array}{l}\text { Cover the works with full } \\
\text { lacquer and dry the works. } \\
\text { Exchange creative ideas, and } \\
\text { complete the questionnaires. }\end{array}$ & $\begin{array}{l}\text { Computer multimedia } \\
\text { equipment, lacquer art } \\
\text { materials, } \\
\text { questionnaires. }\end{array}$ \\
\hline $\begin{array}{c}\text { e-learning Afterschool } \\
\text { learning }\end{array}$ & $\begin{array}{l}\text { Keep posting content related } \\
\text { to the development of } \\
\text { Chinese lacquer art culture } \\
\text { in WeChat groups. }\end{array}$ & $\begin{array}{l}\text { Encourage student } \\
\text { exchanges and pay attention } \\
\text { to the lacquer art activities. }\end{array}$ & $\begin{array}{c}\text { Smartphone or computer, } \\
\text { WIFI. }\end{array}$ \\
\hline
\end{tabular}

The popularization teaching of lacquer art in primary schools commonly includes the step-by-step teaching of lacquer art techniques in order to strengthen students' cognition and feeling for lacquer materials, but within an extremely limited period, and restricted maintaining of techniques' impartment only. Teaching practices based on the e-learning mode can quickly disseminate the latest information resources through the online platforms. Students may use the online platforms to view pictures and professional videos outside of the classroom. They can preview the content in advance, review the knowledge after the class, and choose time and space for study independently, which is beneficial to improving their learning efficiency. More importantly, compared to the traditional classroom mode in which the interaction between teachers and students is mostly limited to the class, e-learning can achieve synchronous or non-synchronous exchanges and interactions between teachers and students through multiple channels, such as email, communication tools, forum platforms, etc. [27], thus forming a sustainable and extended learning model. Under the guidance of teachers, students can use smartphones (or computers) and the Internet to absorb knowledge over time, which also helps to promote knowledge exchange and dissemination, and expands students' interest in the development of lacquer art. From a macro-perspective, a larger population who value lacquer art culture is of great significance to the sustainable development of lacquer art inheritance.

\subsection{Promoting the Sustainable Prospect of Lacquer Art Teaching Based on E-Learning}

In the past, due to temporal and spatial limitations, it was difficult to extend the knowledge about lacquer art culture beyond the traditional classroom, which restricted the further spread of the lacquer art culture in the future. Therefore, in this research, the e-learning model was proposed to encourage students to understand the development of Chinese lacquer art in their spare time through the relevant literature, pictures, videos, and other materials under the guidance of teachers. Through the digital platforms, they can easily learn anytime and anywhere, which has a positive effect on the inheritance and promotion of lacquer art culture. The sustainable development relationship is as follows (Figure 2). 


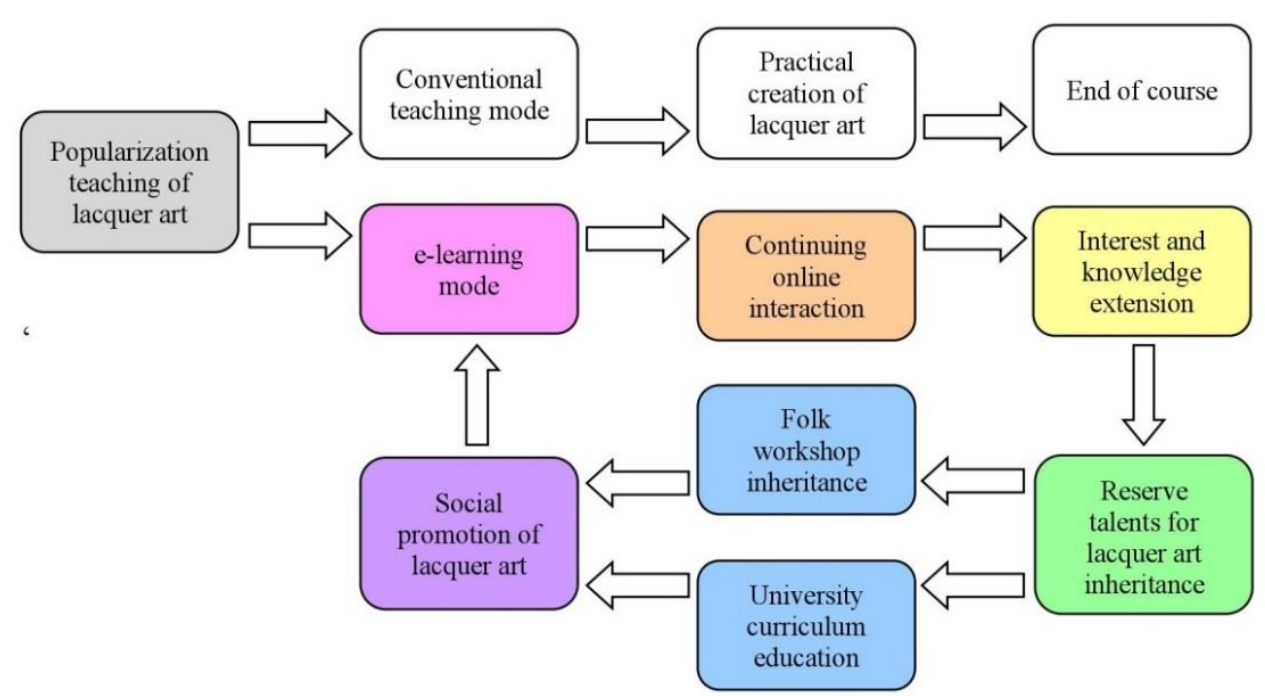

Figure 2. Application of e-learning mode in assisting the sustainable development of lacquer art learning.

Regarding knowledge inheritance, contemporary society has unparalleled advantages. In order to improve the demands for the teaching of various arts and crafts, many museums and art galleries often invite experts and craftsmen to conduct on-site lectures, while more primary and secondary schools have started to offer lacquer art courses. The online publicity media exceed temporal and geographical restrictions, while digital protection provides a technology platform for the display and inheritance of lacquer art [28]. In general, the number of audiences is increasing rapidly, and more people are willing to understand or promote lacquer art culture. In the future, they will be willing to learn more about lacquer art, which enriches the reserve talents to carry forward lacquer art culture [29], thus stabilizing its sustainable development.

\section{Results}

The results of this practical research are summarized mainly from two aspects: The display of work effects and the analysis of survey questionnaires.

\subsection{Display of Work Effects}

Overall, the lacquer art works produced by the students had different shapes and patterns (Figure 3) as the students adopted diversified expressive methods and were quite imaginative and creative in terms of the subject (Figure 4). Based on the knowledge of traditional lacquer art styles, students often chose black or red lacquer as the background color, and then used gold and silver foil to create the picture. However, as the course was short and compactly arranged, the work effects were relatively rough. Students tended to choose simpler lacquer techniques, such as painting, foiling, etc., and were less willing to use a series of complicated processing methods, such as inlaying eggshells and grinding. At the end of the course, after the lacquerware works are completely dried, they were returned to the students to remind them of their participation in the practice of lacquer art. 

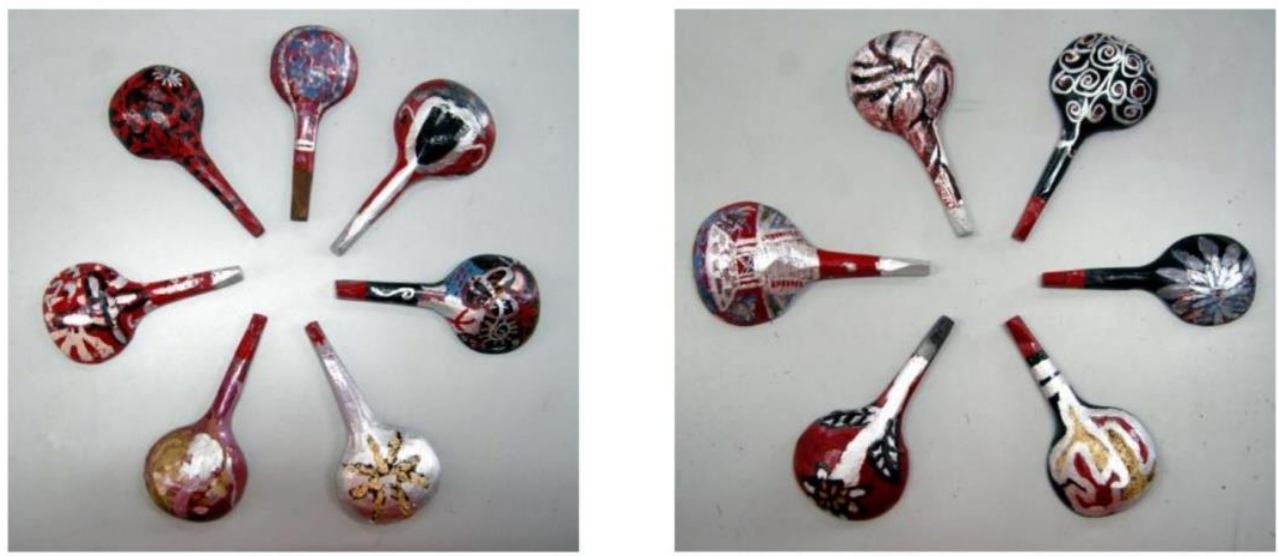

Figure 3. Work effects (Overall effect) of lacquer art practice course.
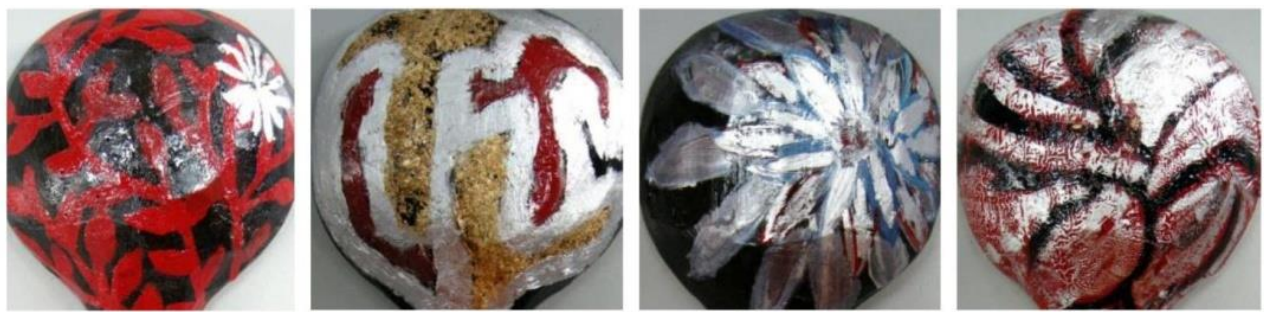

Figure 4. Work effects (Local effect) of lacquer art practice course.

\subsection{Analysis of the Survey Questionnaires}

At the end of the course, all students were invited to fill out the questionnaires (Table 5); then, the data were analyzed (Figure 5). There were 13 questionnaires distributed, and 13 valid questionnaires were recovered.

Table 5. Questionnaire survey results of students in the Guangzhou area.

\begin{tabular}{ccc}
\hline No. & Questionnaire Survey Results of Students in the Guangzhou Area \\
\hline 1 & Before this course, have you been exposed to lacquer art? (If yes, please explain the relevant channels in detail.) \\
A. Yes (7.7\%) & B. No (92.3\%)
\end{tabular}




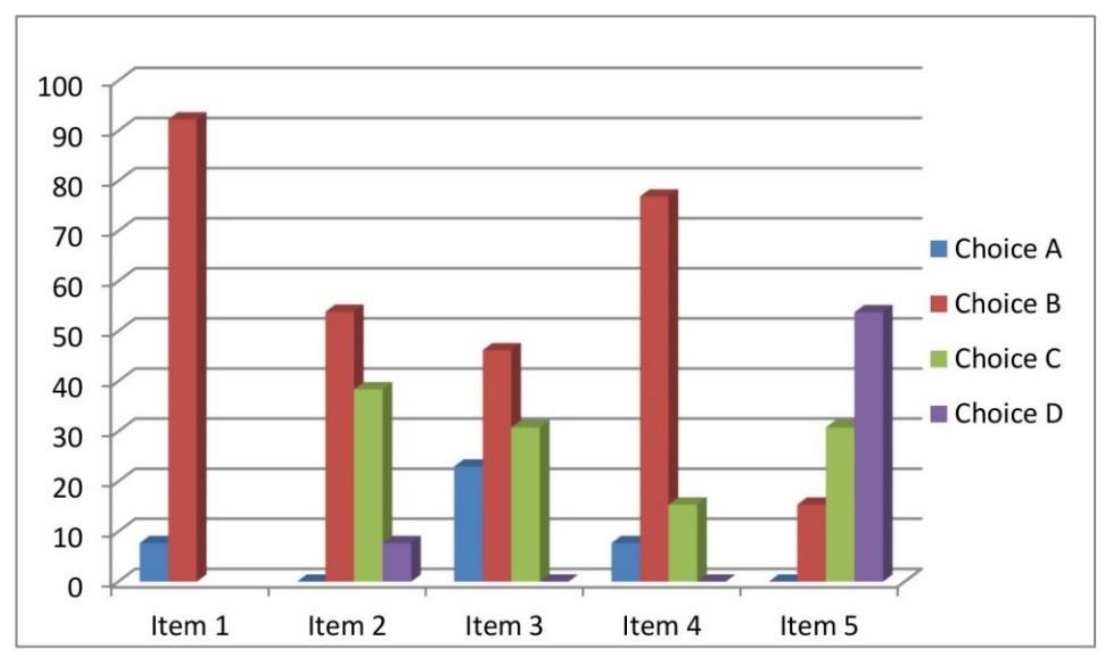

Figure 5. Questionnaire survey results of students.

In general, the important information reflected by the questionnaire survey shows that students had less chance to independently conduct lacquer art in their spare time, and instead, they actively participated in the lacquer art practice in the classroom. Most of them accepted learning about lacquer art after the class via the e-learning mode (Table A2).

Through observations of the creative atmosphere in the classroom, as well as the evaluation of the students' lacquer art works and the review of the questionnaire results, the interest and enthusiasm of the children in the primary schools for Chinese lacquer art culture, as well as their joy of practical experience, originated from the freshness of the lacquer materials and their curiosity about beautiful things.

\section{Discussion}

\subsection{Summary of the Case Study}

This study took the Guangzhou area as the example and aimed to assist students in more efficient study, based on the e-learning mode, in traditional lacquer art teaching during primary school. Meanwhile, based upon the online platform established during the learning process, the researchers expect to continue and extend the lacquer art learning state through after-class teacher-student communication and resource sharing. This performs as a new type of lacquer art inheritance mode proposed under the current information and technology environment.

Based on the researchers' teaching practice research, all of the 13 students who participated in the course had over one year's worth of foundation of fine art learning, while only one of them had ever approached lacquer art in life. Thus, it is deducible that people have few chances to approach lacquer art culture via common social resources at any ordinary time, even for elementary students with fine art specialties.

Students achieved a significant rise in interest in lacquer culture through their personal in-class discovery toward comprehensive materials, and combined after-class online appreciation of lacquer art-related videos, pictures, and other data. They considerably cherished their lacquer works finished in class and were commonly willing to spend their time to give insight into lacquer art culture in their daily life.

In general, based on the establishment of the e-learning teaching mode, more than just providing a chance for lacquer art creation for the participating students, this research even launched a long-term lacquer art communication platform for both teachers and students to constantly share materials concerning lacquer art, and keeping away the possible estrangement that may be caused by the passage of time and special distance. 


\subsection{Significance of Ppersistence and Effectiveness of the E-learning Mode in Lacquer art Education}

Based on a short-term lacquer art practice course, this research puts forward the significance of the e-learning teaching mode in the sustainable development of lacquer art education at the primary school stage. The Guangzhou area boasts rapid IT development, conspicuous strength in rich digital resources, and propagation speed. Starting from the popularization education at the primary school stage, the utilization of advantages in network platform resource sharing to assist lacquer art teaching would gradually enhance the public's cognition of lacquer culture, and if things go on like this, this would achieve utmost facilitation in the sustainable development of lacquer art.

Undoubtedly, the e-learning teaching mode should not only be restricted to the primary school stage. This mode offers the greatest significance in removing the communication barriers in the field of lacquer art, in establishing a platform beneficial for exchange and communication, and in constantly sharing relevant information, presenting access for people of all circles to understand and appreciate lacquer, thus providing abundant newly-emerging followers and reserve forces for lacquer culture development.

\subsection{Research Limitations}

This paper introduced the e-learning mode into the popularization education of lacquer art in order that students can gradually overcome the temporal and spatial limitations, learn autonomously, accumulate more lacquer art knowledge, and spread lacquer culture widely through the advantages of digital platforms, which effectively promotes the sustainable development of lacquer art. However, from the perspective of hardware equipment, the learning mode must be founded on two conditions: (1) smartphone or computer, and (2) smooth urban Internet. Due to differences in objective conditions across the country, in this paper, only the Guangzhou area was used as a reference.

In addition, the promotion of teaching lacquer art in primary schools is more common in extracurricular courses; thus, the number of students participating in practical research is relatively limited, and the time span of the course is relatively narrow. Therefore, this paper can only refer to the cognition and feedback of primary school students participating in the research on the e-learning model, can only apply known data to make reasonable hypotheses and inferences, and can only put forward teaching suggestions to promote the sustainable development of lacquer art in the Guangzhou area. In follow-up research, the researchers will continue to explore this issue in-depth, and to acquire objective research data across a wider range.

\section{Conclusions}

Based on the lacquer art practice course, and according to the teaching content and after-class feedback, this study aimed to put forward effective suggestions that are beneficial to the sustainable development of lacquer art culture. Based on traditional lacquer art creation, the researchers added autonomous learning, thus extending the e-learning model. By analyzing students' acceptance of the model, this study affirms the positive significance of e-learning for the sustainable development of lacquer art in the Guangzhou area.

Under sound intelligent electronic devices and smooth Internet access, with the advantages of convenient and fast communication on the digital platform, it is highly feasible to integrate the e-learning mode into the popularization teaching of lacquer art culture. Students can choose the time and site independently, and can also replay the learning materials in accordance with their own interests, which plays a supporting role in understanding the basic knowledge of Chinese lacquer art culture.

Generally speaking, the time span for lacquer art courses in primary schools is extremely limited; thus, keeping the interest and attention of students can better promote the sustainable development of lacquer art education. Based on the advantages of the contemporary Internet platform, students can learn lacquer art knowledge in the long-term, and can share and forward their knowledge, which 
will also help promote the popularization of the e-learning model, and will eventually increase the audience of lacquer art culture, thus effectively promoting the sustainability of lacquer art.

Author Contributions: Conceptualization, X.-H.L.; methodology, K.-K.F.; validation, M.-J.L.; data curation, M.-J.L.; writing—original draft preparation, X.-H.L.; writing—review and editing, X.-H.L.; supervision, K.-K.F. All authors have read and agreed to the published version of the manuscript.

Funding: This research was funded by Taiwan Ministry of Science and Technology, grant number 108 WFA2610323.

Conflicts of Interest: The authors declare no conflict of interest.

\section{Appendix A}

Table A1. Content analysis of questionnaire survey on lacquer art professionals in the Guangzhou area.

\begin{tabular}{|c|c|}
\hline No. & $\begin{array}{l}\text { Content Analysis of Questionnaire Survey on Lacquer art Professionals in the Guangzhou } \\
\text { Area }\end{array}$ \\
\hline 1 & $\begin{array}{l}\text { How old are you? } \\
\text { Analysis: Most of the respondents were born in the 1980s, followed by the 1990s, and the 1970s. }\end{array}$ \\
\hline 2 & $\begin{array}{l}\text { What is your highest academic qualification? } \\
\text { Analysis: Respondents have all received formal higher education, most of them have a master's } \\
\text { degree, followed by undergraduate degrees, and a few have doctoral degrees. }\end{array}$ \\
\hline 3 & $\begin{array}{l}\text { How were you first exposed to lacquer art? } \\
\text { Analysis: Most of the respondents were exposed to lacquer art for the first time through school } \\
\text { courses. No respondents were exposed to lacquer art for the first time through digital platforms. }\end{array}$ \\
\hline 4 & $\begin{array}{l}\text { Which of the following ways do you prefer to learn about lacquer art? } \\
\text { Analysis: Regarding the access to lacquer art knowledge, most respondents prefer to consult } \\
\text { experts or watch exhibitions, followed by digital platforms. }\end{array}$ \\
\hline 5 & $\begin{array}{l}\text { When was the last time you were exposed to lacquer art (including remote viewing, } \\
\text { understanding the lacquer art theory, etc.)? } \\
\text { Analysis: Most of the respondents had experience with lacquer art within the last week. }\end{array}$ \\
\hline
\end{tabular}

Table A2. Content analysis of questionnaire survey on students.

\begin{tabular}{cc}
\hline No. & Content Analysis of Questionnaire Survey on Students \\
\hline 1 & Before this course, have you been exposed to lacquer art? (If yes, please explain the relevant channels in \\
detail). & Analysis: Only one student in the class had seen lacquerware in a museum. \\
\hline 2 & In the one-week course, which area are you most interested in? \\
& Analysis: Most students are interested in rich lacquer art materials, followed by related lacquer art videos. \\
\hline 3 & $\begin{array}{c}\text { Have you carefully viewed the pictures and videos that the teachers posted on WeChat after class? } \\
\text { them viewed all the pictures and videos completely, but the viewing times were different. }\end{array}$ \\
\hline 4 & $\begin{array}{c}\text { Did you feel burdened when the teacher asked you to take time to view the pictures and videos after class? } \\
\text { Analysis: Over } 80 \% \text { of students easily completed the online learning tasks in their spare time. }\end{array}$ \\
\hline 5 & $\begin{array}{c}\text { In the future, which of the following methods do you prefer to continue to learn about lacquer art? } \\
\text { Analysis: More than half of the students prefer to get more information on lacquer art through online } \\
\text { platforms, followed by movies or TV. }\end{array}$ \\
\hline
\end{tabular}

\section{References}

1. Shi, R.R. Beauty of Lacquer Realm-Lacquer Art Style of Mr. Fan Jun. Art Panor. 2011, 5, 72-73. [CrossRef]

2. Hong, J. Rise and Fall of Beijing's Modern Folk Lacquerware. China Concr. 2001, 6, 25-27. [CrossRef]

3. Chen, W.Y. Fine Carving and Luxury in Hundreds of Years-Study of the Lacquer Art Inheritance and Development of Chaozhou Wooden Carvings. Arts Circ. 2016, 6, 68-69. [CrossRef]

4. Cai, K.Z. Gain New Knowledge by Reviewing Old: 1930-2006 Anthology of Vietnamese Lacquer Paintings, 1st ed.; Lingnan Fine Arts Publishing House: Guangzhou, China, 2018; p. 1. 
5. Lin, X.Y. Path of Lacquer Painting: Work Collection of Chen Zhiqiang, 1st ed.; Lingnan Fine Arts Publishing House: Guangzhou, China, 2016; pp. 82-83.

6. Long, H.; Li, L. Depth of Lacquer Art: 2015 Chinese and Foreign Lacquer Art Collection, 1st ed.; Lingnan Fine Arts Publishing House: Guangzhou, China, 2015; p. 176.

7. Liaw, S.-S.; Huang, H.-M.; Chen, G.-D. Surveying Instructor and Learner Attitudes Toward E-Learning. Comput. Educ. 2007, 49, 1066-1080. [CrossRef]

8. Chiu, C.-M.; Hsu, M.-H.; Sun, S.-Y.; Lin, T.-C.; Sun, P.-C. Usability, Quality, Value and E-Learning Continuance Decisions. Comput. Educ. 2005, 45, 399-416. [CrossRef]

9. Ge, J.X. A Brief Analysis on the Application of E-Learning in Primary and Secondary School Teachers Training. Sci. Ed. Artic. Collect. 2016, 12, 24-26.

10. Jiang, X.M. Learning With Network - E-Learning. J. Weifang Educ. Coll. 2006, 19, 86. [CrossRef]

11. Xu, Y.G.; Zhu, J.J. Research on Application of E-Learning in School Education. J. Xiangyang Vocat. Tech. Coll. 2016, 9, 127-130. [CrossRef]

12. $\mathrm{Xu}, \mathrm{T}$. Research on Interactive Design of Learning Resources. J. Hunan Post Telecommun. Coll. 2015, 14, 32-34. [CrossRef]

13. Govindasamy, T. Successful Implementation of E-Learning Pedagogical Considerations. Internet High. Educ. 2002, 4, 287-299. [CrossRef]

14. Ardito, C.; Costabile, M.F.; De Marsico, M.; Lanzilotti, R.; Levialdi, S.; Roselli, T.; Rossano, V. An Approach to Usability Evaluation of E-Learning Applications. Univers. Access Inf. Soc. 2005, 4, 270-283. [CrossRef]

15. Cai, J.Z.; Jin, H.H. Web Service-Oriented Framework for E-Learning System. J. Yanbian Univ. (Nat. Sci. Ed.) 2006, 32, 55 .

16. Sun, H.X. A Design of Teaching Platform of E-Learning Based on VRML. J. Gansu Norm. Coll. 2012, 17, 88.

17. Xiao, H.Y.; Liu, X.; Zhang, J.G. The Application of E-Learning Service Platform in Primary and Middle Schools. J. Cangzhou Teach. Coll. 2010, 26, 106-107. [CrossRef]

18. Yang, Y. Application of E-Learning Teaching Platform in Teaching Reform of Modern Biological Experimental Technique. High. Ed. Sci. 2019, 89-92.

19. Sun, P.-C.; Tsai, R.J.; Finger, G.; Chen, Y.-Y.; Yeh, D. What Drives a Successful E-Learning? An Empirical Investigation of the Critical Factors Influencing Learner Satisfaction. Comput. Educ. 2008, 50, 1183-1202. [CrossRef]

20. Lee, J.; Song, H.-D.; Hong, A.J. Exploring Factors, and Indicators for Measuring Students' Sustainable Engagement in E-Learning. Sustainability 2019, 11, 985. [CrossRef]

21. Chen, W.Q. The Characterization Analysis and Application Study of E-Learning. Comput. CD Softw. Appl. 2011, 17, 73.

22. Ma, H.N. Analysis and Evaluation Methods of Network Behavior-Based E-Learning. Data Cult. Educ. 2018, 197-198.

23. Li, S.H. On the Basic Concept and Instruction - Design of E-Learning. J. Guangxi Univ. Natl. (Nat. Sci. Ed.) 2002, 8, 37. [CrossRef]

24. Yu, H.B.; Liu, Q.; Yu, X.Q.; Wang, M.H. Related Issues a Preliminary Study of the Questionnaire Research and Evaluation. China J. Pharm. Econ. 2014, 2, 193-196.

25. Wang, Y.L.; Qi, M. Preliminary Study on the Questionnaires and Design Skills of Science Popularization Survey. Sci. Pop. 2010, 1, 37-42.

26. Zhang, T.L.; Zhou, J.B.; Li, L. Discussion on the Question Design in Survey Questionnaires. Sci. Technol. Innov. Her. 2013, 3, 243-244.

27. Cao, W.Q. Role and Prospect of E-Learning in Primary and Secondary Education. China Ed. Innov. Her. 2012, 15, 128. [CrossRef]

28. Sun, K.Q. China's Intangible Cultural Heritage Protection and Sustainable Development. J. Xuzhou Inst. Technol. (Soc. Sci. Ed.) 2013, 28, 62-67.

29. Li, X.; Wu, Z.R. Inheritance Status and System Construction of Regional Intangible Cultural Heritage in Primary and Secondary Education-Case Study of Wuxi. Pop. Lit. Art 2017, 6, 216-217. [CrossRef] 